\title{
RISK FACTORS OF DEVELOPMENT OF HALLUCINATORY-PARANOIDAL DISORDERS IN PATIENTS WITH MIXED DEMENTIA
}

\author{
Shevchenko-Bitensky $K$. \\ SI "Ukrainian Research Institute of Medical Rehabilitation and Balneology \\ of the Ministry of Health of Ukraine"
}

https://doi.org/10.35339/ic.6.3.174-178

\begin{abstract}
Seventy-two patients with Alzheimer's disease (AD) with late onset and vascular brain disease, dementia with hallucinatory-paranoid symptoms (the main group) were examined. The control group included 61 patients with $\mathrm{AD}$ with late onset and vascular disease of the brain without hallucinatory-paranoid symptoms. The risk factors for the development of hallucinatoryparanoid disorders in patients with mixed dementia were determined. These factors included: female gender; age of 78.6 \pm 7.3 years; female history of personality disorders; genetic predisposition to cognitive disorders; neuropathic constitution in childhood; retardation of psychophysical development in childhood; low levels of academic performance; absence of family; secondary and secondary specialized education; a physical type of a job; acute psychogenic factors associated with the worsening of financial conditions, conflicts in the family, and divorce.
\end{abstract}

Keywords: mixed dementia, hallucinatory-paranoid disorders, risk factors, diagnosis.

\section{Introduction}

Modern socio-demographic processes are characterized by an increase in the proportion of elderly persons in populations of different countries $[1,2]$. The results of Ukrainian and foreign studies indicate a high prevalence of cognitive disorders among the elderly persons [3]. The number of patients with mixed dementias (MD), according to various epidemiological data, ranges from $4 \%$ at the age of 70 years and more to $32 \%$ at the age of more than 85 years [4]. Recently, dementia has been defined as one of the main causes of disability and mortality of patients $[1,5]$.

Along with this, in the current literature there is not enough reliable information about the risk factors of the development of psychotic disorders, and in particular hallucinatory-paranoid disorders, in patients with dementia of different origin [3-5]. In contemporary gerontopsychiatry, this issue remains poorly understood, and the available data

Corresponding Author:

Kostyantyn Shevchenko-Bitensky, MD, PhD, Senior Researcher of the SI "Ukrainian Research Institute of Medical Rehabilitation and Balneology of the Ministry of Health of Ukraine. E-mail: 380482@gmail.com describe the risk factors for developing psychosis irrespective of the genesis of dementia. Therefore, the study and determination of the main risk factors of formation of hallucinatory-paranoid disorders in patients with MD is relevant at the modern stage of development of psychiatry.

\section{Purposes, subjects and methods:}

2.1. Purpose - to determine the risk factors for the development of hallucinatory-paranoid disorders in patients with MD.

\subsection{Subjects \& Methods}

The study of risk factors for the development of hallucinatory-paranoid disorders (HPD) in patients with MD was carried out on a sample of 72 patients with F00.1 (1-2); F01.3 (1-2), which formed the main group. Control group included 61 patients with MD without HPD (F00.1; F01.3).

This study involved a set of research methods, which included anamnestic, socio-demographic, clinical-psychopathological, psychometric and mathematical-statistical methods.

The anamnestic method was used to identify the anamnestic factors in the development of HPD in patients with MD. The socio-demographic method involved the study of characteristics such as distribution of patients by age, level of 
education, marital status, educational level, types of job. Clinico-psychopathological method was based on generally accepted approaches to psychiatric examination by interviewing and observing. The survey was conducted using diagnostic and research criteria of ICD- 10 . Selection of patients with MD implied the employment of both the ICD-10 criteria and the criteria developed by the research group of the National Association of Neurological Diseases and Stroke - the International Association for Neuroscience Research and Education (NINDSAIREN) [6]. Psychometric study included the study of the severity of cognitive impairments (normal, physiological aging, mild memory impairment, mild, moderate, moderately severe and severe dementia) using the GDS scale [7]. Statistical data were processed using mathematical t-test method [8]. The method was to conduct a comparative study on the t-criterion according to the traditional method for parametric statistics. Also, the data were processed using t-test to determine the probability of disagreement between the groups [8].

\section{Conflict of interests}

There is no conflict of interests.

\section{Results and discussion}

The investigation of the main characteristics of the object of study (constitutional-biological, socio-demographic and psychosocial) allowed us to identify the main risk factors for the development of HPD in patients with MD.

The results of the analysis of gender distribution among patients with MD of the main and control group are presented in Figure 1.
Among patients with MD and psychotic disorders, women prevailed (76.40\%), while among patients with MD without psychotic disorders the number of women did not exceed the level of $49.20 \%(p<0.05)$. The number of men in the main group of patients with MD with HPD did not exceed $23.60 \%$, and in the control group the number of men reached $50.80 \%(p<0.01)$.

Analysis of the average age ( $\mathrm{M} \pm \sigma$ years) of patients with MD complicated by HPD in comparison with patients with MD without psychotic disorders allowed to determine that patients of age of $78.7 \pm 6.5$ years predominated (at $\mathrm{p}>0.5$ ) in the main group, whereas in the control group they were patients of age $76.3 \pm$ 6.2 years (at $\mathrm{p}>0.5$ ).

The results of the analysis of family history of mental disorders, alcohol and drug dependence among patients with MD with psychotic disorders showed that patients of the main group had family history of hereditary burden of personality disorders (mainly emotionally unstable, paranoid and schizoid) (29.17\%), while in the control group, family history of personality disorders did not exceed the level of $11.48 \%$ of cases $(p<0.01)$ (Table 1).

Family history (genetic predisposition) of cognitive disorders in the patients of the main and control groups was registered in the presence of cognitive disorders ranging from mild cognitive disorders to severe dementia in histories of the closest relatives of these patients.

Assessment of cognitive impairments in the first-line relatives of patients with MD with HPD and patients with MD without HPD, which was

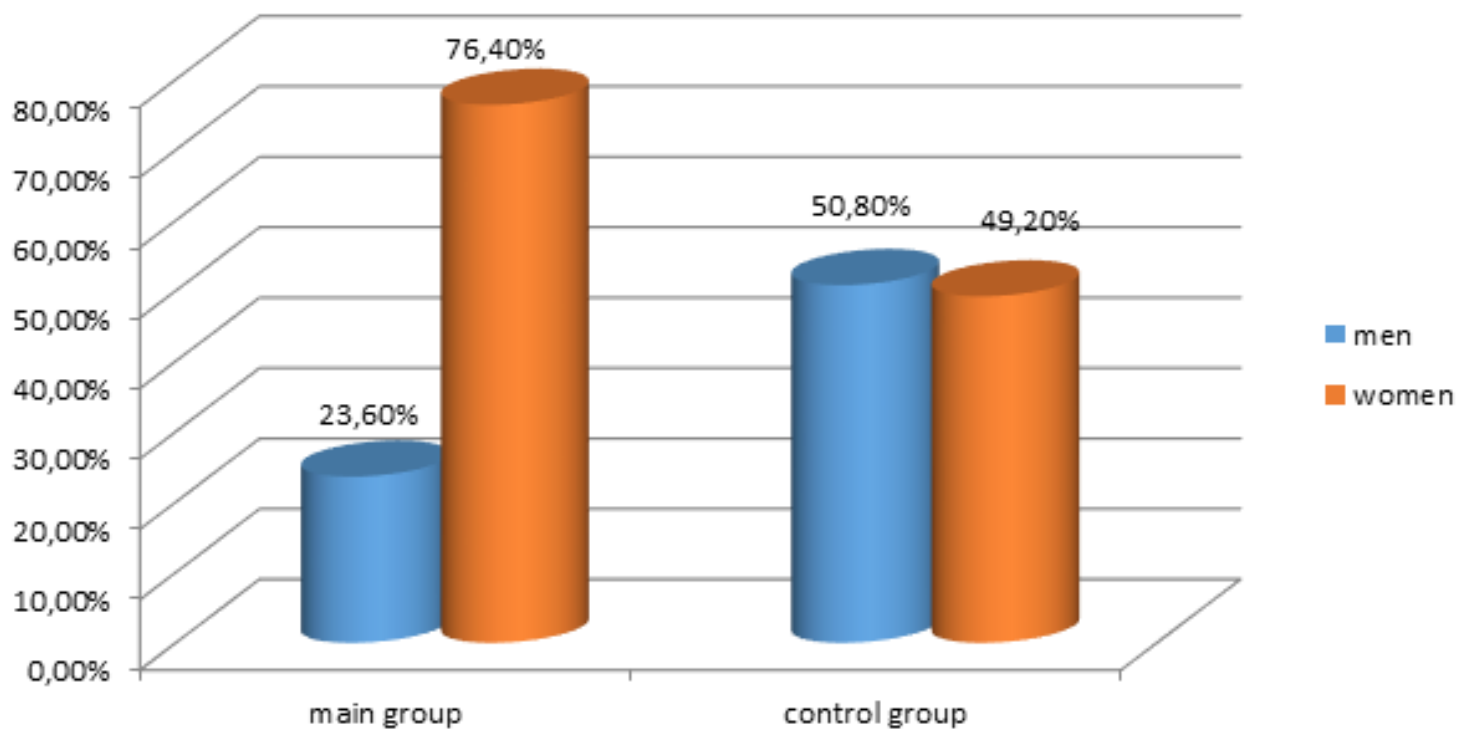

Fig. 1. Distribution of patients with mixed dementia by gender 
Number of patients with dementia with family history

of mental disorders, alcohol and drug dependency

\begin{tabular}{|c|c|c|c|c|}
\hline \multirow{3}{*}{ Name of parameters } & \multicolumn{2}{|c|}{ Main group } & \multicolumn{2}{|c|}{ Control group } \\
\hline & \multicolumn{2}{|c|}{$n=72$} & \multicolumn{2}{|c|}{$n=61$} \\
\hline & Abs. & $\%$ & Abs. & $\%$ \\
\hline Schizophrenia & 1 & 1.39 & 1 & 1.64 \\
\hline Epilepsy & - & - & 1 & 1.64 \\
\hline Somatoform disorders & 7 & 9.72 & 6 & 9.84 \\
\hline Neurotic disorders & 3 & 4.17 & 4 & 6.56 \\
\hline Personality disorders & 21 & $29.17^{*}$ & 7 & $11.48^{*}$ \\
\hline Affective disorders & 12 & 16.67 & 7 & 11.48 \\
\hline Alcohol dependence & 3 & 4.17 & 3 & 4.92 \\
\hline Drug dependence & - & - & 1 & 1.64 \\
\hline
\end{tabular}

performed using clinical and anamnestic methods, showed that in patients of the main group, a genetic predisposition to cognitive disorders was observed in $38.9 \%$ of cases, whereas in patients with MD without psychotic disorders it was observed in $21.3 \%$ of cases $(p<0.05)$.

The results of the investigation of perinatal development (the presence of perinatal pathology in history) among patients with MD with psychotic disorders (the main group) and patients with MD without psychotic disorders (the control group) demonstrated, that $9.7 \%$ of patients in the main group had perinatal pathology, whereas in the control group, perinatal pathology was observed in $21.3 \%$ of patients $(\mathrm{p}<0.01)$.
$33.3 \%$ of patients, while in patients with MD without psychotic disorders there was retardation of childhood psychophysical development in $11.5 \%$ of cases only $(\mathrm{p}<0.01)$.

The analysis of the level of academic performance (at school, secondary specialized and higher educational institutions) of patients with MD revealed that $40.3 \%$ of patients in the main group and $18.0 \%$ of patients in the control group had low levels of academic performance $(\mathrm{p}<0.01)$.

The analysis of the results of investigations of the marital status of patients with MD is presented in Table 2. The table demonstrates, that among patients with MD complicated by HPD, 58.33\%

Table 2

Marital status of patients with mixed dementia (\% $\% m)$

\begin{tabular}{|c|c|c|c|c|}
\hline \multirow{3}{*}{ Marital status } & \multirow{2}{*}{\multicolumn{2}{|c|}{$\begin{array}{c}\text { Main group } \\
\mathrm{n}=72\end{array}$}} & \multirow{2}{*}{\multicolumn{2}{|c|}{$\begin{array}{c}\text { Control group } \\
n=61\end{array}$}} \\
\hline & & & & \\
\hline & Abs. & $\%$ & Abs. & $\%$ \\
\hline Married & 42 & 58.33 & 44 & 72.13 \\
\hline Not married & 30 & 41.67 & 17 & 27.87 \\
\hline
\end{tabular}

The results of the analysis of the prevalence of neuropathic constitution in childhood among patients with MD showed, that in patients with MD complicated by psychotic disorders, neuropathic constitution in childhood was observed in $30.6 \%$ of cases, and in $9.8 \%$ of patients in the control group $(\mathrm{p}<0.01)$. It was also determined that retardation of psychophysical development in childhood was observed in 33.3\% of patients with MD complicated by HPD, and in $11.5 \%$ of cases in the group of patients with MD without psychotic disorders $(\mathrm{p}<0.01)$.

An investigation of the level of psychophysical development in childhood in patients with MD with psychotic disorders showed retardation of psychophysical development in childhood in of patients were married and $41.67 \%$ were not married (single, divorced, widowers / widows), while among patients with MD without psychotic disorders, $72.13 \%$ of patients were married $(p<0.05)$ and $27.87 \%$ were not married $(p<0.05)$.

The results of the analysis of an educational level of patients with MD are presented in Fig. 2 , which shows that patients with secondary (55.6\%) and secondary specialized (29.2\%) educational level prevailed in the main group, while in the control group the number of patients with secondary and secondary specialized education was significantly less $(29.5 \%, \mathrm{p}<0.01$ and $19.7 \%, \mathrm{p}<0.05$, respectively), and with higher (incomplete higher) education was significantly greater $(50.80 \%, \mathrm{p}<0.01)$. 


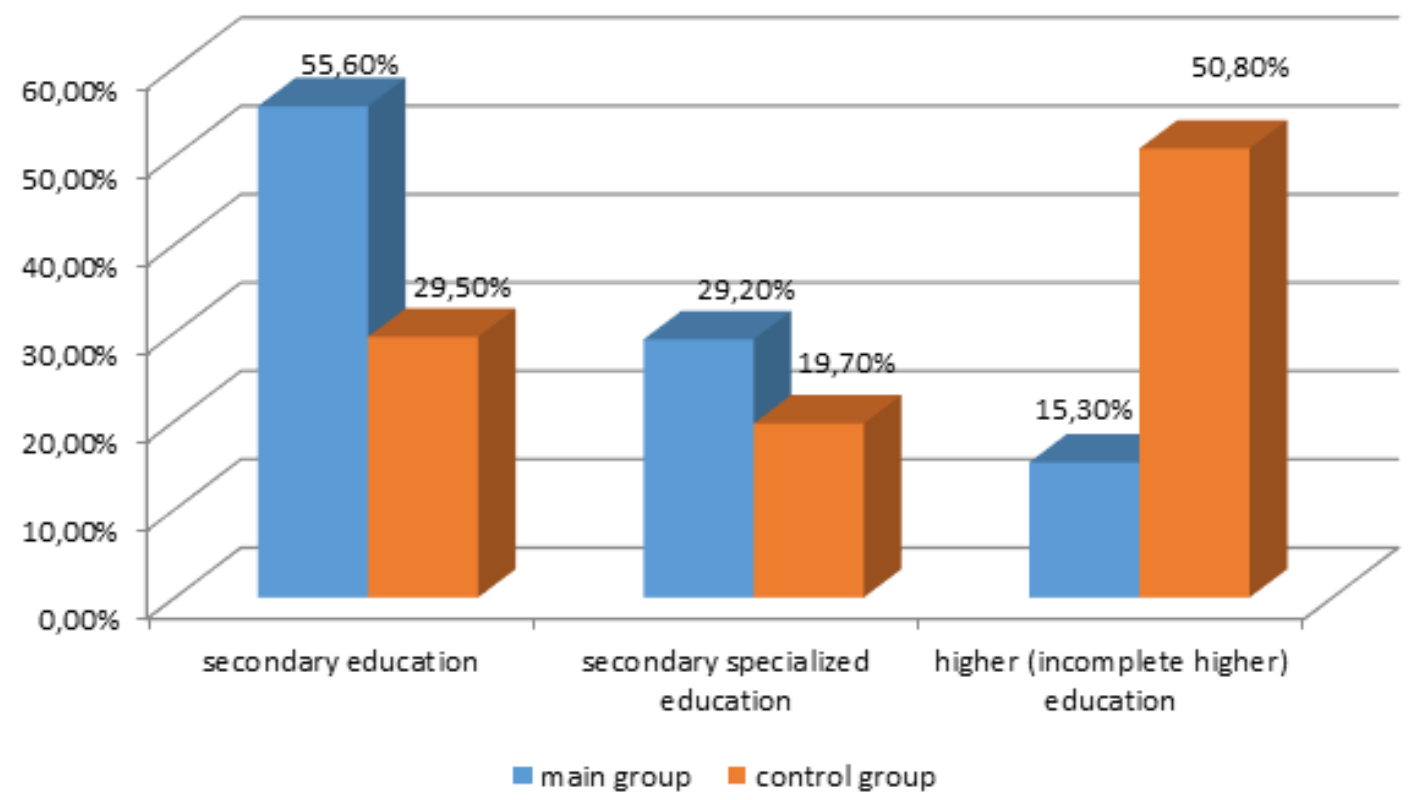

Fig. 2. Educational levels in patients with mixed dementia

The results of investigations of types of job in patients with dementia with psychotic disorders showed that patients with a physical type of job (69.4\%) predominated among patients with MD complicated by HPD, while in the group of patients with MD without psychotic disorders, there were $52.6 \%$ of patients who worked physically $(\mathrm{p}<0.05)$. Accordingly, the number of patients with an intellectual type of job was $30.6 \%$ in the main group and $47.5 \%$ in the control group ( $\mathrm{p}<0.05)$.

The analysis of the main psychogenic factors in patients with MD complicated by HPD showed, that predominant psychogenies in the main group were as follows: a worsening of financial conditions (65.3\%) and conflicts in the family, divorce (63.9\%), whereas in the group of patients with MD without psychotic disorders the psychogenic factor of worsening of financial conditions was registered only in $44.3 \%$ of patients $(\mathrm{p}<0.05)$, and psychogenies related to conflicts in family and divorce were observed in $24.6 \%$ of patients only in the control group $(\mathrm{p}<0.01)$. It should be noted, that among patients with MD complicated by HPD, $48.6 \%$ had a chronic, and $51.4 \%$ had an acute character of psychotraumas, whereas in the group of patients with MD without psychotic disorders, a chronic character of psychotrauma in $75.4 \%(\mathrm{p}<0.05)$ and an acute character in $24.6 \%$ of cases $(p<0.01)$ were defined.

The data are consistent with the results of studies conducted by the commission Lancet which published the nine factors that increase the risk of dementia: social isolation; low level of education; physical inactivity; hypertension; type 2 diabetes; obesity; smoking; ignoring the first signs of depression and middle-aged hearing loss [9]. Authors stated that these factors, which are generally modifiable lifestyle issues, account for about 35\% of the overall risk of dementia [10].

\section{Conclusions}

The study identified risk factors (constitutionalbiological, socio-demographic and psychosocial) of the development of HPD in patients with MD.

These risk factors included:

- female gender;

- age of $78.6 \pm 7.3$ years;

- family history of personality disorders (mostly emotional-unstable, paranoid and schizoid spectra);

- genetic predisposition to cognitive disorders;

- neuropathic constitution in childhood;

- retardation of psychophysical development in childhood;

- low levels of academic performance;

- absence of family (single, divorced, widower/ widow patients);

- secondary and secondary specialized levels of education;

- a physical type of the job;

- acute psychogenic factors associated with a worsening of financial conditions, conflicts in the family, and divorce.

Thus, these identified risk factors for the development of hallucinatory-paranoid disorders in patients with MD should be used to establish algorithms for the diagnosis of HPD in patients with MD and to develop a personalized program for their psychosocial rehabilitation. 


\section{References}

1. Pynchuk Y. (2010) Rasprostranennost' psykhycheskykh rasstroystv v Ukrayne [Prevalence of mental disorders in Ukraine]. Zhurn. AMN Ukrayny. T.16. ${ }^{1}$ 1. P. 168-176.

2. Zilkens R.R., Bruce D.G., Duke J. et al. (2014) Severe psychiatric disorders in midlife and risk of dementia in late-life (age 65-84 years): a population based case-control study. Curr. Alzheimer Res. Vol.11. P. 681-693.

3. Pinchuk I., Chaykovs'ka V., Stadnyk L., Levada O., Pustovoyt M., Shyryayeva M. (2010) Aktual'ni pytannya herontopsykhiatriyi: navchal'nyy posibnyk [Actual questions of the herontopsychiatry: the textbook]. Ternopil': Termohraf. 431 p.

4. Azermai M. (2015) Dealing with behavioral and psychological symptoms of dementia: a general overview. Psychol. Res. Behav. Manag. - Vol. 8. - P. 181-185.

5. Maruta N.O. (2017) Ovladenye obnovlennoy systemoy dyahnostycheskykh podkhodov y kryteryev DSM-5: vozmozhnosty dlya spetsyalystov, rabotayushchykh v sfere psykhycheskoho zdorov ya [Mastering the updated system of diagnostic approaches and criteria DSM-5: opportunities for professionals working in the field of mental health] // Psykhyatryya, psykhoterapyya y kdlynycheskaya psykholohyya. - T. 8. 1 1. - P. 92-103.

6. Roman G.C., Tatemichi T.K., Erkinjuntti T., Cummings J.L., Masdeu J.C., Garcia J.H. et al. (1993) Vascular dementia: diagnostic criteria for research studies. Report of the NINDS-AIREN International Workshop. Neurology. Vol. 43 (2). P. 250-260.

7. Reisberg V., Ferris S.H., M.J. de Leon et al. (1982) The global deterioration scale (GDC). An instrument for the assessment of primary degenerative dementia (PDD). American Journal of Psychiatry. Vol. 139. P. 1136-1139.

8. Gybler E. (1978) Vuchisliteljnue metodu analiza I raspoznavanija patologicheskih processov [Computational methods of analysis and recognition of pathological processes]. Leningrad: Medicina, Leningradskoe otdelenie, $296 \mathrm{p}$.

9. Hampton D. (2018) Nine risk factors associated with dementia. Hearing Review. 25(8). P. 22.

10. Livingston G, Sommerlad A, Orgeta V. (2017) Dementia prevention, intervention, and care. Lancet. 390(10113). P. 2673-2734.

Received: 29-May-2019

Accepted: 03-Aug-2019 